\title{
М. Марушко
}

\section{ТИПОЛОГИЧЕСКИЕ ФУНКЦИИ МУЗЫКАЛЬНО- ИСПОЛНИТЕЛЬСКОГО ДИАЛОГА И СОВРЕМЕННАЯ ИСПОЛНИТЕЛЬСКАЯ ПРАКТИКА}

Статья посвящена проблеме диалога пианиста и дирижёра в процессе исполнения концерта для фортепиано с оркестром как одного из видов творческой коммуникации; выявляются типологические признаки и функции музыкального диалога. Материалом служат две исполнительские интерпретации М. Аргерих Третьего фортепианного концерта С. Прокофьева в творческом содружестве с дирижёрами А. Превином и К. Аббадо.

Ключевые слова: музыкально-исполнительская интерпретация, исполнительский диалог, фортепианный концерт, С. Прокофьев, М. Аргерих, А. Превин, К. Аббадо.

В основе любой интерпретации лежит личностное отношение к предмету интерпретации, то есть его особое, персональное понимание. Исполнительская интерпретация всегда есть своего рода самовыражение художника. Благодаря своему чувственному опыту исполнитель делает художественное произведение более интересным и многообразным, затрагивает глубины подсознания слушателя.

Интересующая нас проблема диалога пианиста и дирижёра находится непосредственно в плоскости решения проблемы интерпретации. В данной статье внимание сфокусировано на творчестве выдающейся пианистки нашего времени - Марте Аргерих, а именно на её интерпретациях Третьего фортепианного концерта С. Прокофьева с не менее известными дирижёрами Андре Превином и Клаудио Аббадо.

Марта Аргерих - из числа тех музыкантов, которым подвластна музыка любого направления и любой сложности. Её исполнение всегда интеллектуально, самобытно, в высшей степени виртуозно, свидетельствует об изумительной технике.

Обе названные интерпретации М. Аргерих позволяют убедиться в том, что отличные друг от друга творческие концепции дирижёров дают возможность пианистке достигать построения двух различных семантических моделей одного и того же концерта, каждая из которых, оставаясь самобытной, соответствует драматургии композиторского текста.

(C) Марушко М., 2015 
Концерт, по сути своей, - явление диалогическое. Исполнительство - тоже. Исполнитель находится в постоянном диалоге с музыкой, композитором и слушателем. Концерт предполагает также диалог с дирижёром и, соответственно, оркестром. Для каждого человека диалог является неотъемлемой частью жизни, для музыканта же диалог - единственная форма творческого художественного самовыражения.

Диалог как важная составляющая музыкально-исполнительской интерпретации имеет свои особенности. Если для художника материалом интерпретации становятся видимый окружающий мир, природные явления, затем пробуждённые отношениями с ними игра воображения и личные переживания, а для писателя - сложные взаимодействия исторической, социальной и личностной детерминант жизненного опыта, то для музыканта-исполнителя объективной средой и базовым материалом является текст музыкального произведения, созданный и предпосланный иным автором, то есть чужой, но осваиваемый и присваиваемый в процессе исполнения как создания новой звучащей формы музыкального текста. Здесь можно провести аналогию с учением Платона об «идеях», тогда последовательность идея - предмет - изображение предмета будет тождественна последовательности культурно-исторический опыт - авторский текст (композиторская интерпретация) - исполнительская интерпретация.

Таким образом, для самого понятия интерпретации коммуникативный фактор является изначальным. Интерпретация сама по себе есть диалог. Последний бывает нескольких типов и может принимать различные формы. Так, существует четыре основных типа диалога диалог согласия, диалог разногласия, «диалог глухих», диалог «по умолчанию». Данная типология оказывается достаточной для обозначения модификаций музыкально-исполнительской интерпретации в современной практике.

Диалог согласия предполагает сближение позиций участников диалога в их побуждении совместно достичь главного адресата (нададресата) диалога. Диалог разногласия мотивирован стремлением создать в процессе коммуникации ощутимое напряжение, связанное с интенциональной выделенностью сознания каждого из субъектов диалога.

«Диалог глухих,, как наиболее сознательно эгоцентричная форма коммуникации, является основой парадоксальных концепций и невозможен в ансамблевом или оркестрово-симфоническом исполне- 
нии. Однако как прерогатива творческих усилий музыканта-солиста он способен служить проводником новых полистилистических - полисемантических концепций.

Диалог «по умолчанию» - ностальгическая форма, опосредованно осуществляющая связь с традицией путём стилизации или подражания, в том числе миметического воссоздания иной, не своей, музыкально-исполнительской интерпретации.

Если оценивать диалогические аспекты музыкального исполнительства с позиции слушателя, можно сказать, что наиболее удачной формой диалога между солистом и дирижёром является диалог разногласия, который возможен только тогда, когда исполнители «сочувствуют» друг другу, ощущая себя в этот момент создателями нового семантического пространства, в котором рождаются новые смыслы.

Ярким примером такого диалога, на наш взгляд, являются две исполнительские интерпретации Марты Аргерих, рассматриваемые в данной статье. Концептуально различные, они суть проявление высокой творческой свободы, одновременно способности к глубокой эмпатии каждого из исполнителей, что позволяет направлять личностно-стилевые интенции к воссозданию единого целостного художественного замысла, к достижению смыслового над-адресата как наивысшей цели творческого диалога.

Отличительной чертой исполнительской интерпретации М. Аргерих - А. Превина является их полное согласие друг с другом в отношении концепции концерта, что ощутимо благодаря органичности их исполнения, их мимике и жестам. Говоря об их интерпретации как о диалоге и сотворческом взаимодействии, нужно отметить, что оба исполнителя оказываются движимыми друг другом, в соответствии с контекстом исполняемого ими произведения, а также одновременно словно растворяются в музыкальном звуковом потоке, превращая тем самым собственное исполнение в некое сакральное действо.

Третий фортепианный концерт Сергея Прокофьева - одно из явлений жанра, вполне соответствующее первоначальному значению слова концерт: соревнование, предполагающее равноценность партий фортепиано и оркестра. Можно обнаружить, что фортепианная партия уже сама по себе оркестральна; это связано с симфоническим мышлением композитора и даёт возможность говорить о фортепиано как об инструменте-оркестре. Однако при этом оркестровая партия не является сопровождающей или фактурно облегченной: это вполне самостоятельный план музыкальной выразительности, представ- 
ляющий мастерскую игру инструментальными тембрами. Нередким явлением становится обмен ведущими динамическими функциями между фортепианной и оркестровой партиями. Встречаются эпизоды, в которых фортепиано выступает как часть оркестра с особой темброво-колористической окраской. Тем не менее, даже в такие композиционные моменты С. Прокофьев не лишает исполнителяпианиста технических трудностей; наоборот, он усиливает их, указывая тем самым на важное значение виртуозности в исполнительском оснащении пианиста.

Таким образом, можно сказать, что Третий концерт является не чем иным, как концертом-симфонией или симфонией для фортепиано с оркестром.

По сути дела мы сталкиваемся здесь с тем обстоятельством, что партия фортепиано и партия оркестра вполне равноправны и равнозначны по функциям. Кроме того, в данном контексте можно говорить о взаимозависимости данных партий. Иногда сольная партия такова, что не особо нуждается в помощи оркестра, ибо сама по себе фактурно усложнена и, соответственно, темброво разнообразна, что позволяет говорить об её оркестральности. Встречаются и такие эпизоды, когда оркестр выступает как главное действующее лицо. В таких случаях пианисту ничего не остаётся, как следовать за дирижёром, ибо последний - не только организатор темпоритма, но и создатель динамического поля.

На примере Третьего фортепианного концерта явно ощутимо, что Сергей Прокофьев - композитор, обладающий чутким симфоническим слухом и оркестровым мышлением. Это подтверждается как артикуляционными, так и фактурными приёмами внутри фортепианной партии. И одни, и другие находятся в прямой зависимости от оркестрового тембра, то есть инструмента и его штриховой палитры. Это означает, что С. Прокофьев трактует фортепиано как инструмент-оркестр, где каждый регистр и каждый тембр имеют свой аналог в оркестре, а артикуляция зависит от того, какой из штрихов характерен для каждого инструмента.

Интерпретация Аргерих - Превина особенно привлекательна именно с точки зрения взаимодействия пианиста с дирижёром, то есть их сотворческого диалога. Анализируя данное исполнение, можно обнаружить, что пианистка в большинстве случаев следует за дирижёром, стремясь трактовать концерт в наибольшем соответствии с композиторским замыслом. 
Диалог Марты Аргерих и Андре Превина очень интересен для стилистического исполнительского анализа. Нужно сказать, что пианистка по своей натуре харизматична и вполне проявляет на сцене волевые качества солистки. В то же время для неё важнее не она сама, а её взаимодействие (взаимопонимание) с дирижёром, ради воплощения общей идеи и достижения главного смыслового над-адресата как наивысшей цели творческого диалога. Можно заметить, что, помимо своей собственной агогики в явно сольных эпизодах, пианистку интересует дирижёрский замысел, его цельность в отношении всего произведения, а потому Аргерих нередко находится в «плену» агогики дирижера.

Оценивая исполнение этого же концерта с Клаудио Аббадо, мы обнаруживаем иную трактовку. Диалог Аргерих - Аббадо создает особое семантическое пространство, напоминая скорее лирико-эпическое повествование с элементами героики. При погружении в мир прокофьевской музыки в воображении, как наяву, проносятся картины героического прошлого родины композитора. Именно эта образная сфера выходит здесь на первый план, а игровое, комическое, праздничное - лишь небольшие зарисовки, которые вплетаются в канву основной сюжетной линии.

Интерпретация Аргерих - Превина полна игры, веселья, юмора (а иногда и гротеска) и особого лиризма медленных эпизодов; интерпретацию Аргерих - Аббадо можно характеризовать как героическую поэму.

Звучащий исполнительский текст позволяет заметить, что там, где Андре Превин создаёт атмосферу игры (всё происходит не всерьёз, понарошку) и привносит элементы театральности, для Клаудио Аббадо вполне серьёзно «веют вихри» трагического прошлого. Сфера лирического также представлена различно: в интерпретации А. Превина она приобретает романтические черты; в семантике исполнительской формы, создаваемой К. Аббадо, - окутана одновременно и сказочными (IV вариация из II части: волшебное озеро в ледяной пещере), и былинными образными ассоциациями (тема вступления из I части, V вариация из II части); предполагает картинность и изобразительные аллюзии (побочная партия III части: тема восхода солниа).

В связи с этим важным компонентом исполнительского интерпретативного пространства становится композиционно-организующая позиция дирижёра. Помимо общих для пианиста и дирижёра 
групп приёмов (фразировка, артикуляция, темпоритм, динамика) существуют индивидуальные: для пианиста - это туше и педализация; для дирижёра - управление тембровыми модуляциями оркестра (выведение на первый план того или иного инструмента, группового тембра) и определение динамических функций оркестра на различных этапах развития музыкального произведения.

Третий концерт - единственный трёхчастный концерт С. Прокофьева, хотя вторая часть его отнюдь не является лирическим центром. Она написана в форме вариаций, которые сменяют одна другую, создавая последовательность образов (как героических, так и лирических). В целом концерту присуща мозаичность характеров. В нём с удивительной лёгкостью уживаются шутовская весёлость и гротеск, лирическое и героическое, не противореча, но обусловливая друг друга.

Нужно сказать, что в то время как Андре Превин выводит на первый план игровую сферу, Клаудио Аббадо акцентирует внимание на тех образах, которые связаны с лирической и героической сферами. Благодаря этому возникает различие в понимании и трактовке III части концерта. В интерпретации Аргерих - Превина III часть становится утверждением радости (побочная партия) и достижением в финале экстатического веселья. В интерпретации Аргерих - Аббадо лирическая побочная партия становится долгожданным рассветом после ночной бури, а финал - торжеством света и победой жизни над смертью.

Исполнительское искусство предполагает наличие у исполнителя ярко выраженного волевого начала. Это относится как к солисту, так и к дирижёру. Солист должен суметь повести за собой, в то время как дирижёр, являясь организатором темпоритма, должен достаточно глубоко понимать, чего хочет солист, какова его концепция. В отличие от сольного исполнительства, диалогические параметры которого достаточно свободны, в данном случае диалог может быть основан только на взаимном заинтересованном и осознанном понимании.

Можно выделить два основных типа дирижёров:

дирижёры, которые в первую очередь стремятся воплотить концепцию солиста;

дирижёры, которые склонны вступать в полемику с солистом ради воплощения своей собственной концепции.

В свою очередь, существуют солисты с различной выраженностью волевых качеств. Нередко дирижёры сталкиваются с тем обстоятель- 
ством, что солист просто-напросто не знает, чего он хочет, но, в силу своих амбиций, не желает прислушаться ко мнению дирижёра. В таких случаях исполнение не становится интерпретацией, так как нет чёткой концепции, а есть лишь ощущение неясности из-за случайных спонтанных «разногласий».

Солисты, которые достойны наименования интерпретаторов, создают новое семантическое пространство, подчиняя себе весь звуковой поток, в то же время следуя за музыкой и постигая ее имманентные свойства. Их исполнение всегда логически выстроено, одновременно увлекает, обладая качеством суггестии, предполагает избыточность смысловых значений и означений. С такими солистами дирижёр не может и, как нам кажется, не должен быть главным действующим лицом. Однако его роль от этого не становится менее ответственной, наоборот, дирижёру предоставлена серьёзная миссия - быть создателем новой концепции, даже если она всецело расходится с его собственным первоначальным замыслом. Для этого солист должен суметь убедить дирижёра.

В качестве примера приведём небольшой фрагмент из воспоминаний английского дирижёра Адриана Боулта. Боулт рассказывает, как однажды ему довелось исполнять ре-минорный концерт И. С. Баха с Вальтером Гизекингом. Перед началом репетиции «Гизекинг вышел на эстраду старого «Куинсхолла» и с ужасом воззрился на сидевших рядами примерно семьдесят струнников - они ждали начала концерта ре-минор Баха. Этот концерт я всегда рассматривал (и исполнял с другими солистами) как сочинение полнокровное, энергичное... В ответ на вопрос Гизекинга я сказал, что оркестр умеет аккомпанировать, и предложил, чтобы узнать его мнение, проиграть одну часть. Когда мы кончили играть, он всё ещё находил, что оркестрантов слишком много... продолжал считать фактуру неправильной. Слово «фактура» поразило меня, и я сказал: «Господин Гизекинг, как вы думаете: этот концерт - фортепианный или клавесинный?» Он вскочил и ответил, что хотя ему и приходится играть на громадном концертном рояле, который мы ему предоставили, он всё время думает о клавесине. Я отослал примерно пятьдесят музыкантов домой, а оставшиеся двадцать играли «вполголоса», к полному удовольствию Гизекинга. Он спросил меня затем, понравился ли мне концерт в таком звучании. «Я всегда считал этот концерт более полнокровным сочинением, - признался я, - но счастлив, что наша публика... имела возможность услышать иную трактовку» [1, с. 164]. 
Кроме всего прочего, дирижёру легко работать со знающим своё дело исполнителем. Более того, именно при таких условиях возможен диалог двух художников (диалог разногласия), создающих музыкально-звуковое пространство, наделённое определённой знаковостью, где рождаются новые смыслы. Собственно, для того и существует искусство, чтобы в определённой системе знаков выразить индивидуальное понимание сущности бытия, индивидуальный образ мира, свою философию жизни и искусства в ней.

Различие между двумя интерпретациями обнаруживается благодаря разности исполнительских приёмов. К ним относятся темпоритм, агогика, динамика, фразировка и артикуляция. Эти основные составляющие музыкального исполнительства дают жизнь музыкальному произведению и являются частями одного целого, которое мы именуем «музыкально-интонационный комплекс» (в терминологии А. Малинковской). Последний есть инструментом для смыслового наполнения произведения, то есть для создания его семантической нагрузки.

Различие трактовки связано также с внутренним состоянием исполнителя, с его самоидентификацией в данное время в данном месте. Понимание личностного «я» и «я-другого» (будь то композиторский текст или другой исполнитель) как своего собственного является важным критерием оценки художественного материала.

Нужно заметить, что, в отличие от других искусств (литературы, живописи, скульптуры и архитектуры), музыка - это то искусство, которое оживает во времени. Она становится осязаемой в пространстве лишь тогда, когда принимает звучашую форму. Это говорит о том, что музыкальное искусство невозможно без исполнительства. Если пространственные искусства «общаются» со своим реципиентом напрямую, то музыка, разворачиваясь во времени, немыслима без посредника в лице исполнителя. В то же время роль исполнителя в музыкальном искусстве не ограничивается только лишь донесением до слушателя композиторского авторского текста. Музыкальное исполнительство, как и любое другое исполнительство, всегда индивидуально и может представлять полярные семантические конфигурации, показывая, таким образом, различные интерпретации одного и того же текста.

Во всех своих композиционно-драматургических тенденциях музыка - самое условное искусство, поскольку лишена вербализации и может быть определена как система знаков, обращенных к опыту 
чувственного сознания. Тем самым она ближе прочих художественных форм связана с представлениями о человеческой душе и с эстетической потребностью пробуждать «лучшие чувства».

По словам А. Ф. Лосева, музыка - это «подвижное единство в слитости» и «текучая цельность во множестве». «Оттого музыка способна вызывать слёзы - неизвестно по поводу какого предмета; способна вызывать отвагу и мужество - неизвестно для кого и для чего; способна внушать благоговение - неизвестно к кому. Здесь слито всё, но слито в своей какой-то нерасчленимой бытийственной сущности. ... Можно переживать, но нельзя отчетливо мыслить эти предметы». Лосев также пишет, что «чистое» музыкальное бытие находится вне пространства, «есть бытие хаотическое и бесформенное. ...Это сплошная неуловимость и в то же время всеприсутствие...» [3, с. 209-210].

Исполнительский диалог солиста и дирижёра, становясь объектом изучения, обнаруживает особые качественные критерии оценки, обусловленные, в том числе, отличием исполнительской формы концерта с оркестром от сольного произведения. Если в последнем случае пианист волен в выборе темпа, динамики, артикуляции и фразировки, то в диалоге с дирижёром он должен преднамеренно отказаться от мысли, что только от него зависит всё «происходящее». В связи с этим целесообразно опять вернуться к вопросу о том, в какой степени в жанре концерта представлены принципы солирования.

Концерт как творческий диалог исполнителя и дирижёра, становясь предметом изучения и структурного анализа, в качестве главного инструмента формообразования обнаруживает организацию темпоритма, ответственность за которую всецело лежит на дирижёре. Рассматривая две различные трактовки Третьего фортепианного концерта С. Прокофьева, в качестве критериев оценки изберем те исполнительские средства, которые используют дирижёры для воплощения целостного художественного замысла.

А. Малинковская, говоря о тоно-процессуальной энергии как о важной составляющей фортепианного исполнительства, предлагает деление пианистов на такие типы, выявляя их качественные отличия: Виртуоз; Лирик; Повествователь; Импровизатор; Актёр (режиссёр, драматург); Странник; Архитектор (зодчий, строитель); Замедлитель времени; Мыслитель. Стараясь разобраться, какой из типов мог бы стать наиболее подходящим для дирижёрского исполнительства, мы пришли к выводу, что таковым является Архитектор. Вот определение, которое даёт А. Малинковская: «Зодчие - выдающиеся стратеги 
формы; они всегда - «над текущим моментом»; большая перспектива, распахивающая пространство, сжимает и тем самым напрягает, что и заставляет вибрировать тоно-процессуальную энергию. У исполнителей данного типа преобладают формо-«кристаллизующие» принципы охвата целого, своего рода дедуктивная работа мысли от общего к частному. Изначально схватывая отношения в крупных масштабах формы, они тренируют в своём мышлении механизмы обобщения-сжатия... мышление «большими единствами» заставляет их... использовать темпоритм как своего рода рычаг формосозидания» $[4$, с. 174].

Однако дирижёр является не только формосозидателем, но и субъектом, который организует время в его единстве и множественности, в его неделимости (цельности) и раздельности. Музыка есть выражение времени со всеми его коррелятивными инструментами: подвижностью и покоем; слитностью и делимостью.

Таким образом, важнейшим качеством такого рода исполнительского диалога является организованная темпоральность, управление параметрами времени, предвидение и предчувствие длительности и динамики движения. Понимание и предчувствие - вот опорные свойства исполнительского диалога между солистом и дирижёром, позволяющие охватить звучащий музыкальный поток целиком, то есть осознать его форму, чтобы затем определить ключевые моменты данной формы и придать им семантическую определенность. Естественно, что каждый дирижёр (да и вообще исполнитель) будет проставлять смысловые акценты на тех слагаемых («участках») формы, которыми, по его мнению, наиболее обусловлена основная идея произведения.

В случае с концертом С. Прокофьева обнаруживается возможность по-разному воспринимать композиторский текст, то есть отмечать в партитуре различные опорные моменты, и, исходя из этого, предлагать ту или иную трактовку произведения. Говоря о двух вышеназванных интерпретациях данного концерта, мы можем с уверенностью констатировать, что у Андре Превина и Клаудио Аббадо опорные точки расставлены различно. Если Превин всё время старается придать концерту беззаботно-игровой характер, облегчая (везде, где только возможно) оркестровую фактуру, то Аббадо, придавая большое значение сфере героических образов, часто на первый план выводит группу медных духовых инструментов, которая у Превина в большинстве случаев оказывается сглаженной. 
В целом можно обозначить две линии критериев, по которым мы оцениваем и сравниваем обе интерпретации, рассматривая их как творческий диалог: 1) темпоритмическая сторона как организация времени; 2) тембровая выразительность, отвечающая за динамическую сторону развития музыкального произведения и становящаяся величиной, обладающей концепционной значимостью.

Нужно сказать, что темпоритм музыкального произведения в процессе исполнения будет зависеть от внутреннего биоритма исполнителя. Театральный педагог и кинорежиссёр С. В. Гиппиус в книге «Тренинг развития креативности. Гимнастика чувств» предлагает шкалу разных темпоритмов, в которых может находиться человек (актёр), условно разделив их на 10 градаций. Среди них он называет предельную пассивность, «постепенный переход к бодрому самочувствию», готовность к любому действию, темпоритм «настороженного внимания», «лихорадочный пульс жизни», потеря способности осознавать и регулировать свои действия [3]. Притом эти темпоритмы способны сменять друг друга в процессе действия. Для харизматической личности (в данном случае таковой является как дирижёр, так и солист) наиболее характерными обнаруживаются темпоритм «настороженного внимания» (ему свойственны решимость, быстрота реакции на смену настроения и т. д.) и «готовность к любому действию». Они являются удобными для творческого взаимодействия, что и наблюдается в рассмотренных нами выше интерпретациях.

Ощутимо, что в процессе исполнения биоритмы солистки и дирижёров созвучны друг другу, потому можно обозначить данный процесс как художественное вчувствование или творческую эмпатию.

Всё вышесказанное даёт нам возможность обозначить несколько ключевых моментов исполнительского процесса и позволяет сделать такие выводы:

1) диалог, обнаруживая различные формы, является неотъемлемой частью музыкально-исполнительского искусства. Наиболее качественной формой диалога между солистом и дирижёром является диалог разногласия, который возможен только при наличии у исполнителей ярко выраженной интенциональности, а также эмпатических качеств, благодаря которым музыканты достигают целостности художественного замысла;

2) концерт как творческий диалог солиста и дирижёра важным компонентом интерпретативного пространства обнаруживает композиционно-организующую позицию дирижёра; последний являет- 
ся как формосозидателем, так и организатором времени (темпоритма). Важнейшими качествами такого рода исполнительского диалога являются предвидение и предчувствие длительности и динамики движения;

3) различие интерпретаций, обнаруживаемое в ходе сравнительного анализа, определяется внутренним состоянием и степенью сосредоточенности исполнителей (дирижёра и солиста) на темпоритмической стороне процесса, следовательно, и их способностью преврашать чувствуемое (слышимое) время в феномен музыкального звучания.

\section{СПИСОК ЛИТЕРАТУРЫ}

1. Боулт А. Мысли о дирижировании // Исполнительское искусство зарубежных стран. Вып. 7 / [сост. Г. Эдельман; ред. Л. Баренбойм]. - М.: Музыка, 1975. - C. 164.

2. Гиппиус С. В. Тренинг развития креативности. Гимнастика чувств [Электронный pecypc]. - Режим доступа: http://psylib.ukrweb.net/books/ gippi01/index.htm

3. Лосев А. Ф. Музыка как предмет логики // Лосев А. Ф. Из ранних произведений. - М.: Правда, 1990. - С. 209-210.

4. Малинковская А. В. Класс основного музыкального инструмента. Искусство фортепианного интонирования: учеб. пособие. - М.: Владос, 2005. - C. 174.

Марушко М. Типологічні функції музично-виконавчого діалогу і сучасна виконавська практика. Стаття присвячена проблемі діалогу піаніста та диригента у процесі виконання концерту для фортепіано з оркестром як одного з видів творчої комунікації; виявляються типологічні чинники та функції музичного діалогу. Матеріалом служать дві виконавські інтерпретації М. Аргеріх Третього фортепіанного концерту С. Прокоф'єва у творчій співдружності з диригентами А. Превіном та К. Аббадо.

Ключові слова: музично-виконавська інтерпретація, виконавський діалог, фортепіанний концерт, С. Прокоф’єв, М. Аргеріх, А. Превін, К. Аббадо.

Marushko M. Typological functions of music and performing dialogue and modern. performing practice. The article deals with the problem of dialogue pianist and conductor in the performance of Concerto for piano and orchestra as one of the types of creative communication; typological factors and features musical dialogue. As a material are performing two interpretations of the S. Prokofiev Third Piano Concerto by M. Argerich in creative collaboration with conductors K. Abbado.and A. Previn

Keywords: musical and performing interpretation, performing dialogue, Piano Concerto, S. Prokofiev, M. Argerich, A. Previn, C. Abbado. 